\title{
Music Preferences across Different Socio-Economic Classes in Selected Urban and Sub Urban Areas of Sri Lanka
}

\author{
B.I.L.M.Mendis ${ }^{1}$, P.A.D.S Palihaderu ${ }^{1}$, D. A. Satharasinghe ${ }^{1}$, J. M. K. J. K. Premarathne ${ }^{2}$, A.S. \\ Dissanayake $^{3}$, H.Rajapakse ${ }^{4}$, P.Karunanayaka ${ }^{5}$, U. Senarath ${ }^{6}$, W.Wijesuriya ${ }^{7}$ W.K.R.R.Dias ${ }^{8 *}$ \\ ${ }^{1}$ Department of Basic Veterinary Sciences, Faculty of Veterinary Medicine and Animal Science, University of \\ Peradeniya, Peradeniya 20400, Sri Lanka \\ 2 Department of Livestock and Avian Sciences, Faculty of Livestock, Fisheries and Nutrition, Wayamba \\ University of Sri Lanka, Makandura, Gonawila (NWP) 60170, Sri Lanka \\ ${ }^{3}$ Department of Clinical Medicine, Faculty of Medicine, University of Ruhuna, Galle, Sri Lanka \\ ${ }^{4}$ Department of Psychiatry, Faculty of Medicine, University of Ruhuna, Galle, Sri Lanka \\ ${ }^{5}$ Department of Clinical Medicine, Faculty of Medicine, University of Colombo, Colombo 08, Sri Lanka \\ ${ }^{6}$ Department of Community Medicine, Faculty of Medicine, University of Colombo, Colombo 08, Sri Lanka \\ ${ }^{7}$ Biometry Section, Rubber Research Institute of Sri Lanka, Dartonfield, Agalawatta 12200, Sri Lanka \\ ${ }^{8}$ Department of North Indian Music, Faculty of Music, University of the Visual and Performing Arts, Colombo \\ 07, Sri Lanka
}

\begin{abstract}
The preferences towards music have socio-psychological influences. Thus, this study was undertaken to investigate musical preferences across five different social classes; upper class, upper middle class, middle class, working class and poor class in selected urban and suburban areas of Sri Lanka $(\mathrm{N}=75)$. The social classes were categorized according to the mean monthly national household income level of the Sri Lankans. Ten tracks representing the correspondent musical genres were selected namely: new age, romantic instrumental, gypsy music, jazz, folk, hip-hop, Indian classical, western classical, rock and nature music. The preferences were evaluated using the frequency percentages of the most preferred track along with the mean scores of a 9 point hedonic scale. Moreover, the ART-ANOVA statistical test was conducted to determine the interactions between social classes and music preferences. The most preferred and mean of hedonic scale rated music genres in each class as upper class: jazz with $40 \%$; 6.87( \pm 2.00$)$, upper middle class: nature music $33 \%$; $7.20( \pm 1.28)$, middle class: romantic instrumental $27 \% ; 6.86( \pm 1.73)$, working class: romantic instrumental $33 \%$; $6.8( \pm 1.37)$, poor class: rock $40 \%$; $6.53( \pm 2.3)$, respectively. The interaction between social classes and genres was significant with a $\operatorname{Pr}(>F)$ value of $0.0036(p<0.01)$. Despite the socio-economic status, the highest music preference was recorded as the romantic instrumental 23\%; 7.02 $( \pm 1.27)$ across all classes. The tonal and melodic elements of romantic instrumental genre may be the key fundamentals of music perception. Thus, the findings of this study warrant further studies in their music selection in the context, people across different socio-economic backgrounds.
\end{abstract}

Keywords: socio-economic background; musical preferences; genres; hedonic scale; music selection

Acknowledgments: This research was funded by the World Bank under the AHEAD Operation. 